\title{
Discovery of two new phases of zirconium tetrakis(8-hydroxyquinolinolate): synthesis, crystal structure and their electron transporting characteristics in organic light emitting diodes (OLEDs) $\dagger$
}

\author{
Poopathy Kathirgamanathan, ${ }^{* a}$ Sivagnanasundram Surendrakumar, ${ }^{a}$ Juan Antipan-Lara, ${ }^{a}$ \\ Seenivasagam Ravichandran, ${ }^{a}$ Vanga R. Reddy, ${ }^{a}$ Subramaniam Ganeshamurugan, ${ }^{a}$ Muttulingam Kumaraverl, ${ }^{a}$ \\ Vincent Arkley, ${ }^{a}$ Alexander J. Blake ${ }^{* b}$ and Daniel Bailey ${ }^{b}$
}

Received 12th August 2010, Accepted 1st November 2010

DOI: 10.1039/c0jm02644a

\begin{abstract}
Two new phases of zirconium tetrakis(8-hydroxyquinolinolate) $\left(\mathrm{Zrq}_{4}\right)$ have been synthesised and characterised by single crystal X-ray diffraction. Their electrical, electronic, optical and thermal properties have been studied. Their electron transporting characteristics have been investigated in organic light emitting devices where the two phases show remarkable differences in performance. One of the forms (designated $\alpha-\mathrm{Zrq}_{4}$ ) gives significantly lower operating voltage, higher efficiencies and longer lifetime than the other (designated $\beta-\mathrm{Zrq}_{4}$ ) in organic light emitting devices.
\end{abstract}

\section{Introduction}

Organic light emitting diode (OLED) based displays have become one of the significant flat panel display technologies as evidenced by the production of active matrix OLEDs for mobile phones by Samsung SDI and the introduction of an 11" AMOLED TV (XEL-1) to the market by Sony. Recent announcement by Samsung of its intention to invest US Dollars 2.2 billion into active matrix OLED televisions (AM-OLED) to bring them into the mainstream TV market has given considerable impetus to the scientists developing materials for the OLED devices.

Long operational lifetime and high electroluminescent efficiencies are very important to commercial success. OLEDs are multilayer devices, typically composed of (i) a hole injector (e.g. copper phthalocyanine $\quad(\mathrm{CuPc}), \quad 4,4^{\prime}, 4^{\prime \prime}$-tris $[N$-(2-naphthyl)- $N$-phenylamino)-triphenylamine (2-TNATA), tripyrazinocyclohexane(s), ${ }^{1-3}$ (ii) a hole transporter (e.g. $N, N^{\prime}$-bis-(1-naphthalenyl)- $N, N^{\prime}$-bisphenyl-(1,1'-biphenyl)-4, $4^{\prime}$-diamine, $\alpha$-NPB), (iii) an emissive layer (host + dopant), (iv) an electron transporter (e.g. tris(8-hydroxyquinoline)-aluminium $\left(\mathrm{Alq}_{3}\right)$ ), (v) an electron injector (e.g. LiF, $\mathrm{CsF}$, lithium quinolinolates) and (vi) a cathode (e.g. Al $)^{46}$ to provide charge balance so that efficient devices can be produced. Hole transporters and electron transporters can also be doped with an acceptor or a donor, respectively, to increase the conductivities of the respective layers. ${ }^{5,6}$

There are continuing demands for reductions in power consumption and operating voltage of OLEDs and for lengthening their lifetime. Charge transport (hole and electron) materials, whether pure or doped, are an integral part of any OLED.

${ }^{a}$ Organic Electronics, Wolfson Centre, Brunel University, Kingston Lane, Uxbridge, UB8 3PH, UK. E-mail: p.kathir@brunel.ac.uk

${ }^{b}$ School of Chemistry, The University of Nottingham, University Park, Nottingham, NG7 2RD, UK

$\uparrow$ Electronic supplementary information (ESI) available: synthetic routes to, and ${ }^{1} \mathrm{H},{ }^{13} \mathrm{C}$ NMR and mass spectra of, zirconium tetrakis(8-hydroxyquinolinate) $\left[\alpha-\mathrm{ZrQ}_{4}\right.$ and $\beta-\mathrm{ZrQ}_{4}$ forms]. CIF for crystal structure and crystal packing. CCDC reference numbers 798048 and 798049. For ESI and crystallographic data in CIF or other electronic format see DOI: 10.1039/c0jm02644a
It has been reported that nearly $60 \%$ of the total electric power is lost through the charge transport layers, nearly $36 \%$ through the electron transporting layer, 5.7\% through the electron injecting layer and the remainder through the hole injection layer, hole transporting layer and hole blocking layer. ${ }^{8}$ The lifetime is also critically dependent on the nature of the charge transporters employed. Improvements in efficiencies of up to $70 \%$ were reported by Kathirgamanathan et al. ${ }^{1}$ and Kido et al. ${ }^{7}$ when $\mathrm{Alq}_{3}$ was replaced by some novel electron transporters in otherwise identical devices.

A good electron transporter (et) should have the following characteristics: ${ }^{10-13}$ (i) high electron affinity to match with the work function (W.F.) of the cathode, thus reducing the energy barrier; (ii) high electron mobility $\left(\mu_{\mathrm{e}}>1 \times 10^{-5} \mathrm{~cm}^{2} \mathrm{~V}^{-1} \mathrm{~s}^{-1}\right)$ to aid the transport of electrons into the emissive layer and efficiently confine the excitons in this layer; (iii) a reversible electrochemical reduction with a sufficiently high reduction potential; (iv) a high ionisation potential (I.P.) to serve as a hole blocker (I.P. > $6 \mathrm{eV}$ ); (v) a high glass transition temperature and melting point; (vi) thermal stability up to at least $250^{\circ} \mathrm{C}$ (high $T_{\mathrm{g}} /$ $T_{\mathrm{m}} / T_{\mathrm{d}}$ ); (vii) stability under evaporation conditions for a period of at least 144 hours if vacuum processing is employed; (viii) good stability to moisture and oxygen; (ix) be capable of forming amorphous films so that crystallisation induced degradation is avoided; (x) photostability; (xi) if phosphorescent emitters are used, the triplet energy level of the et should be higher than that of the phosphorescent emitters; (xii) processability to produce uniform and pinhole-free films either by evaporation (small molecules) or by solution casting.

A variety of electron transporters based on metal quinolinolate(s) (e.g. $\mathrm{Alq}_{3}, \mathrm{Inq}_{3}, \mathrm{Gaq}_{3}, \mathrm{Scq}_{3}, \mathrm{Mgq}_{2}$ ), oxadiazole(s), imidazole(s), pyridine derivatives, perfluorinated oligophenylene(s), silole(s), phenanthroline(s), boron compounds and pyrimidone(s) have been reported., ${ }^{7,-12,14,17-21}$ However, $\mathrm{Alq}_{3}$, despite its low electron mobility and instability to holes, has remained the material of choice due to low cost and acceptable OLED lifetime. However, $\mathrm{Alq}_{3}$ has three major drawbacks: (i) it leaves behind a considerable amount of residue during sublimation purification 
and OLED production conditions; (ii) the operating voltage is still relatively high and (iii) the perceived toxicity of aluminium compounds.

We have been working on charge transporting materials for OLEDs over the last 10 years and have discovered that zirconium tetrakis(8-hydroxyquinolinolate) $\left(\mathrm{Zrq}_{4}\right)$ not only acts as a good electron transporter, but also lowers the operating voltage and increases the lifetime and efficiency of OLED devices compared to tris(8-hydroxyquinoline)aluminium $\left(\mathrm{Alq}_{3}\right) .{ }^{1,15}$ The stability of $\mathrm{Alq}_{3}$ is attributed to the fact that at least two isomers ( $\mathrm{fac}$ and mer) are always present in any $\mathrm{Alq}_{3}$ sample, thereby preventing crystallisation during device operation. The avoidance of crystallisation is important for long device lifetime. ${ }^{16}$ It is also important to note that $\mathrm{Alq}_{3}$ also exists in several forms, denoted by $\alpha-\mathrm{Alq}_{3}, \beta-\mathrm{Alq}_{3}, \gamma-\mathrm{Alq}_{3}$ and $\delta-\mathrm{Alq}_{3} \cdot{ }^{26} \mathrm{Zrq}_{4}$ was found to be stable in OLED production equipment at elevated temperature $\left(300{ }^{\circ} \mathrm{C}\right)$ for over 6 weeks under production conditions without undergoing any decomposition, residue or ash formation, ${ }^{29}$ as established by sampling the material periodically and measuring its properties such as absorption coefficient (extinction coefficient), fluorescence, mass and NMR (proton and ${ }^{13} \mathrm{C}$ )

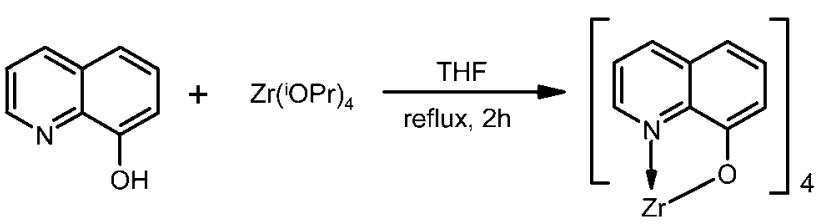

Scheme 1 Synthesis of $\alpha-\mathrm{Zrq}_{4}$.

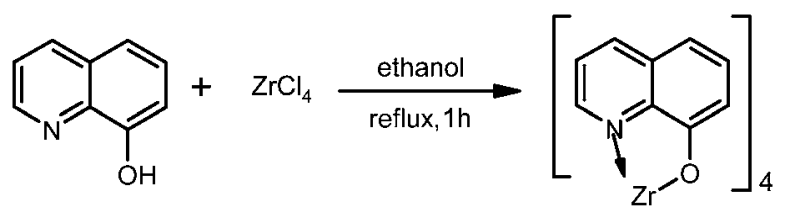

Scheme 2 Synthesis of $\beta-\mathrm{Zrq}_{4}$. spectroscopy and elemental analysis. This extraordinary stability of $\mathrm{Zrq}_{4}$ under production conditions (vacuum thermal evaporation) led us to further investigate its characteristics.

The device performance of $\mathrm{Zrq}_{4}$ was found to be remarkably dependent on the preparation conditions and the starting materials. Therefore, we reasoned that there must be at least two phases or isomers of $\mathrm{Zrq}_{4}$ existing in the samples, depending on the conditions of synthesis. This paper describes the journey to identify the different phases of $\mathrm{Zrq}_{4}$ and their effect on the performance of OLED devices.

It is well known that the preparation method could influence the electrical and electronic properties of a material, so we examined the effect of the nature of starting materials, namely $\mathrm{ZrCl}_{4}, \mathrm{Zr}\left(\mathrm{O}^{\mathrm{i} P r}\right)_{4}, \mathrm{Zr}\left(\mathrm{O}^{n} \mathrm{Bu}\right)_{4}$ and zirconium tetrakis(2,2,6,6-tetramethyl-3,5-heptanedionate $\left(\mathrm{Zr}(\mathrm{tmhd})_{4}\right)$, and the solvents namely ethanol, acetonitrile, phenylcyanide, dichloromethane, toluene and tetrahydrofuran. In the course of this work, we discovered that there are at least two forms of $\mathrm{Zrq}_{4}$ and only one form (monoclinic, herein after called the $\alpha$ form, from $\mathrm{Zr}\left(\mathrm{O}^{\mathrm{i}} \mathrm{Pr}\right)_{4}$ as the starting material) is more electron transporting than $\mathrm{Alq}_{3}$. The other form (orthorhombic, herein after called the $\beta$ form, from $\mathrm{ZrCl}_{4}$ as starting material) is less electron transporting than $\mathrm{Alq}_{3}$. This paper describes the synthesis and their physical properties, performance in electroluminescent devices and the differences in the conduction mechanisms in selected comparable OLED devices. We have also made comparison with $\mathrm{Alq}_{3}$, purchased from H.W. Sands (USA) and possibly containing a mixture of different phases of $\mathrm{Alq}_{3}$, but after purification by double sublimation.

\section{Experimental}

\section{Synthesis}

The $\alpha$ form was synthesised by refluxing 8-hydroxyquinoline with zirconium isopropoxide in THF while the $\beta$ form was synthesised by reacting 8 -hydroxyquinoline with zirconium(IV)

Table 1 For both structures: $\mathrm{C}_{36} \mathrm{H}_{24} \mathrm{~N}_{4} \mathrm{O}_{4} \mathrm{Zr}, M_{\mathrm{r}}=667.81, Z=4$. Experiments were carried out with Mo $K \alpha$ radiation $(\lambda=0.71073 \AA)$ using a Bruker SMART1000 CCD area detector diffractometer. H-atom parameters were constrained

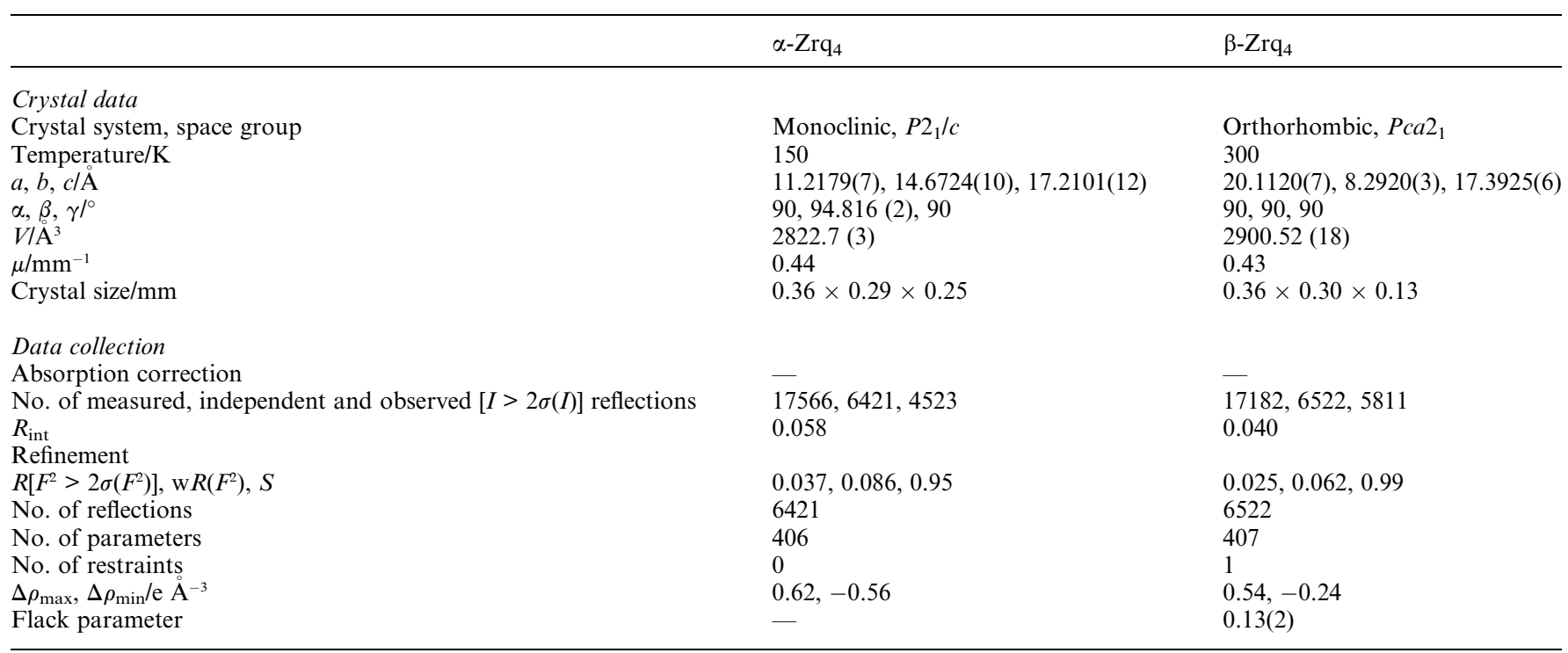


chloride (Scheme 1 and 2). $\mathrm{Zrq}_{4}$ was purified by quadruple sublimation at $280^{\circ} \mathrm{C}$ under vacuum (pressure of $1 \times 10^{-6}$ Torr).

\section{Device fabrication}

Electron-only devices were fabricated by evaporating the $\mathrm{Zrq}_{4}$ to produce a layer thickness of $400 \mathrm{~nm}$ onto $\mathrm{Mg} / \mathrm{Al}$ coated ITO/ glass and sandwiching it with a bottom contact of another layer of $\mathrm{Mg} / \mathrm{Al}(200 \mathrm{~nm})$. $\mathrm{Alq}_{3}$ devices were also made for comparison.

Electroluminescent devices were fabricated by thermal evaporation method using a multi-chamber OLED pilot plant machine (Solciet, manufactured by ULVAC, Japan). The devices were fabricated on a patterned pixelated ITO substrate $(40 \mathrm{ohms}$ per square surface resistance, Hitachi High Tech., Japan), cleaned with water, acetone, isopropyl alcohol and water (in that order), then dried at $150{ }^{\circ} \mathrm{C}$ for 20 minutes and then subjected to ozone cleaning (UV irradiation, $185 \mathrm{~nm}$ ) at $150{ }^{\circ} \mathrm{C}$ for 10 minutes. The substrate was then plasma cleaned in the presence of oxygen for 25 seconds and moved into the vacuum chamber from which the hole injector [5,10,15,20-tetra( $p$-tolyl)-21 $\mathrm{H}, 23 \mathrm{H}$ porphine zinc(II) (ZnTPTP), $50 \mathrm{~nm}]$, hole transporter [ $N, N^{\prime}$-bis(1-naphthalenyl)- $N, \quad N^{\prime}$-bis-phenyl-(1,1'-biphenyl)-4,4'-diamine, $(\alpha-\mathrm{NPB}), 50 \mathrm{~nm}]$, host : dopant $\left[\mathrm{Alq}_{3}(50 \mathrm{~nm}):(0.1 \mathrm{~nm}) N, N^{\prime}-\right.$ diphenylyquinacridone (DPQA), co-evaporation], and electron transporter [either $\mathrm{Alq}_{3}$ or $\mathrm{Zrq}_{4}(20 \mathrm{~nm})$ ] were sequentially deposited. The evaporation rates of ZnTPTP, $\alpha-\mathrm{NPB},\left(\mathrm{Alq}_{3}\right.$, DPQA), $\mathrm{Zrq}_{4}$ and LiF (electron injector) were $1 \AA \mathrm{s}^{-1}, 1.5 \AA \mathrm{s}^{-1}$, $\left(1 \AA^{-1}, 0.1 \AA \mathrm{s}^{-1}\right), 1 \AA^{-1}, 0.05 \AA \mathrm{s}^{-1}$, respectively.
Directly from the vacuum chamber all the devices were encapsulated with a UV curable adhesive (Nagase) with glass backplates in a glovebox filled with dry nitrogen so that the device is not exposed to air. The electrical and optical measurements were carried out by a computer-controlled Keithley 2400 Source Meter and a Minolta (CS-1000) spectrometer, respectively. HOMO-LUMO levels were determined by cyclic voltammetry (by computer controlled potentiostat PAR 273 or CHI 600D) and from band gap measurements by absorption spectroscopy of thin films produced by vacuum thermal evaporation. Capacitance measurements were made on thin films as well as compacted discs using an Impedance Analyser (Hewlett Packard, 4284A).

\section{Crystal structure analysis}

Single crystals of both $\alpha-\mathrm{Zrq}_{4}$ and $\beta-\mathrm{Zrq}_{4}$ were grown by slow vacuum sublimation at a temperature of $275^{\circ} \mathrm{C}$ and a pressure of $5 \times 10^{-6}$ Torr.

$\mathrm{X}$-Ray crystallographic studies were carried out on single crystals of $\alpha-\mathrm{Zrq}_{4}$ and $\beta-\mathrm{Zrq}_{4}$ : data collections ${ }^{24}$ were performed at 150 and $300 \mathrm{~K}$, respectively, as $\omega$ scans on a Bruker SMART1000 CCD area detector diffractometer, using graphite-monochromated Mo- $K \alpha$ radiation $(\lambda=0.71073 \AA$ ). Data were corrected for Lorentz and polarization effects. ${ }^{25}$ The structures were solved by direct methods using SHELXS97, ${ }^{26}$ developed by iterative cycles of least-squares refinement and difference Fourier synthesis, and refined by full-matrix least-squares on $F^{2}$ using SHELXL97. ${ }^{26}$ Crystallographic Information Files were prepared using enCIFer ${ }^{27}$ and validated using PLATON. ${ }^{28}$ All non-hydrogen atoms were

Table 2 Summary of synthesis conditions and yields for zirconium complexes

\begin{tabular}{llllllll}
\hline Material & Reagent & Solvent & Base & Synthesis yield (\%) & Soxhlet extraction yield (\%) & Sublimation yield (\%) & Overall yield (\%) \\
\hline$\alpha-\mathrm{Zrq}_{4}$ & $\mathrm{Zr}\left(\mathrm{COPr}_{4}\right)_{4}$ & $\mathrm{THF}$ & None & 88 & Not needed & 91 & 80 \\
$\beta-\mathrm{Zrq}_{4}$ & $\mathrm{ZrCl}_{4}$ & Ethanol & Piperidine & 93 & 77 & 92 & 66 \\
\hline
\end{tabular}
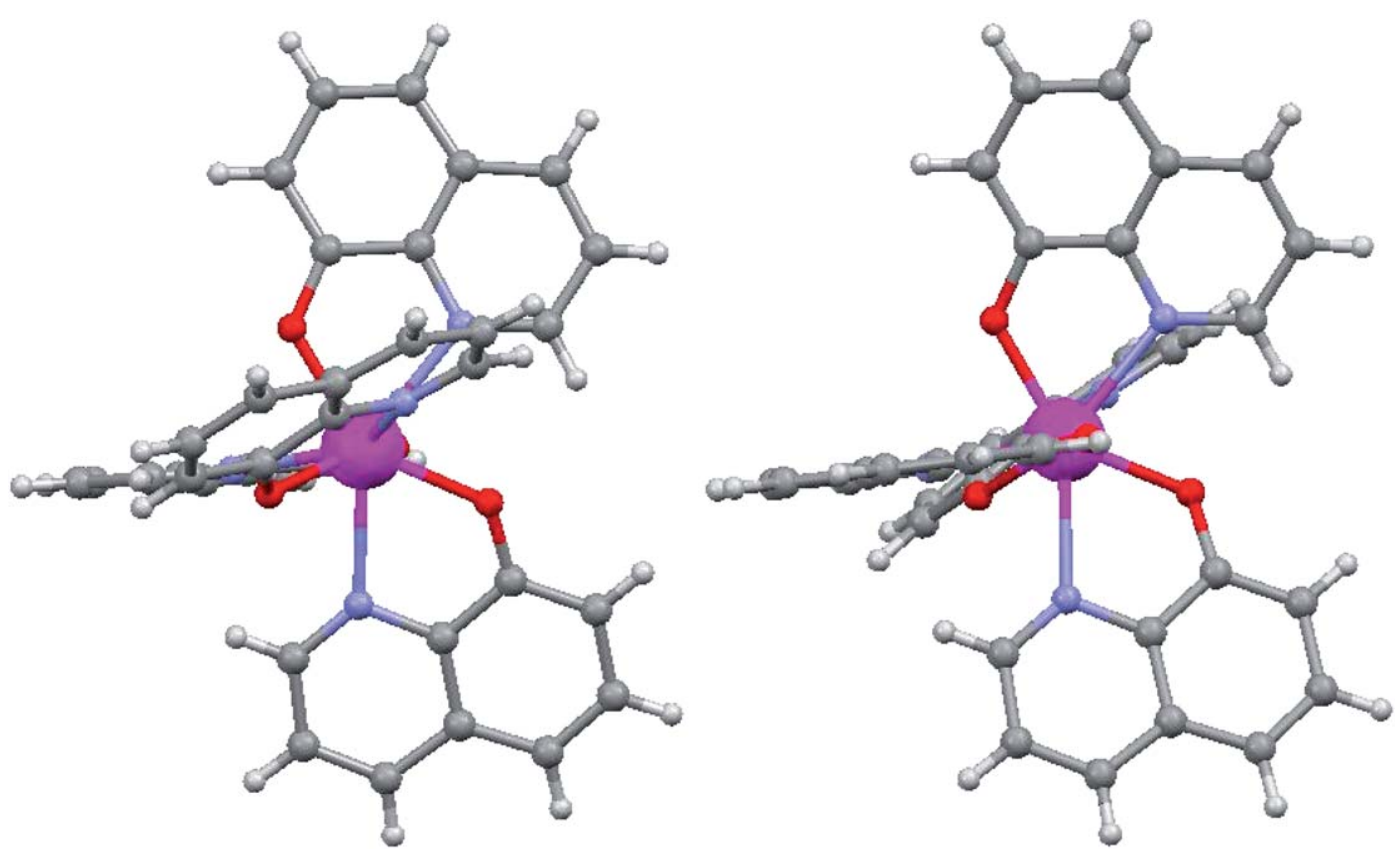

Fig. 1 Crystal conformations for $\alpha-\mathrm{Zrq}_{4}$ and $\beta-\mathrm{Zrq}_{4}$. 
refined anisotropically. Hydrogen atoms were introduced at geometrically calculated positions and refined using a riding model with $\mathrm{U}_{\text {iso }}(\mathrm{H})=1.2 \mathrm{U}_{\mathrm{eq}}(\mathrm{C})$. Crystal data and structure refinement details are summarised in Table 1.

\section{Results and discussion}

The synthesis of $\mathrm{Zrq}_{4}$ has been reported by Frazer and Rimmer, ${ }^{22}$ who also prepared $\mathrm{Hfq}_{4}$, by reacting $\mathrm{ZrCl}_{4}$ with 8-quinolinol in THF, first producing $\mathrm{Zrq}_{4} \cdot 2 \mathrm{hq}(\mathrm{hq}=8$-hydroxyquinoline) and then $\mathrm{Zrq}_{4}$ upon sublimation purification. An X-ray crystal structure determination of $\mathrm{Zrq}_{4} \cdot 3$ toluene has been reported by Lewis and Fay. ${ }^{23}$

Table 3 Selected geometric parameters $\left(\AA,^{\circ}\right)$

\begin{tabular}{|c|c|c|c|}
\hline \multicolumn{4}{|l|}{$\alpha-\mathrm{Zrq}_{4}$} \\
\hline $\mathrm{Zr} 1-\mathrm{O} 1$ & $2.110(2)$ & $\mathrm{Zr} 1-\mathrm{N} 1$ & $2.425(2)$ \\
\hline $\mathrm{Zr} 1-\mathrm{O} 2$ & $2.097(2)$ & $\mathrm{Zr} 1-\mathrm{N} 2$ & $2.462(2)$ \\
\hline $\mathrm{Zr} 1-\mathrm{O} 3$ & $2.096(2)$ & $\mathrm{Zr1-N3}$ & $2.473(2)$ \\
\hline $\mathrm{Zr1-O} 4$ & $2.120(2)$ & $\mathrm{Zr1-N4}$ & $2.419(2)$ \\
\hline $\mathrm{O} 1-\mathrm{Zr} 1-\mathrm{O} 2$ & $91.25(6)$ & $\mathrm{O} 3-\mathrm{Zr} 1-\mathrm{N} 1$ & $74.48(6)$ \\
\hline $\mathrm{O} 1-\mathrm{Zr} 1-\mathrm{O} 3$ & $141.49(6)$ & $\mathrm{O} 3-\mathrm{Zr} 1-\mathrm{N} 2$ & $75.48(6)$ \\
\hline $\mathrm{O} 1-\mathrm{Zr} 1-\mathrm{O} 4$ & $95.14(6)$ & $\mathrm{O} 3-\mathrm{Zr} 1-\mathrm{N} 3$ & $69.57(6)$ \\
\hline $\mathrm{O} 1-\mathrm{Zr} 1-\mathrm{N} 1$ & $70.02(6)$ & $\mathrm{O} 3-\mathrm{Zr} 1-\mathrm{N} 4$ & $141.71(7)$ \\
\hline $\mathrm{O} 1-\mathrm{Zr} 1-\mathrm{N} 2$ & $82.06(6)$ & $\mathrm{O} 4-\mathrm{Zr} 1-\mathrm{N} 1$ & $74.55(6)$ \\
\hline $\mathrm{O} 1-\mathrm{Zr} 1-\mathrm{N} 3$ & $148.74(7)$ & $\mathrm{O} 4-\mathrm{Zr} 1-\mathrm{N} 2$ & 149.93(6) \\
\hline $\mathrm{O} 1-\mathrm{Zr} 1-\mathrm{N} 4$ & $74.27(6)$ & $\mathrm{O} 4-\mathrm{Zr} 1-\mathrm{N} 3$ & $78.53(6)$ \\
\hline $\mathrm{O} 2-\mathrm{Zr} 1-\mathrm{O} 3$ & $109.16(7)$ & $\mathrm{O} 4-\mathrm{Zr} 1-\mathrm{N} 4$ & $69.92(7)$ \\
\hline $\mathrm{O} 2-\mathrm{Zr} 1-\mathrm{O} 4$ & $140.43(7)$ & $\mathrm{N} 1-\mathrm{Zr} 1-\mathrm{N} 2$ & $76.40(6)$ \\
\hline $\mathrm{O} 2-\mathrm{Zr} 1-\mathrm{N} 1$ & $143.20(6)$ & $\mathrm{N} 1-\mathrm{Zr} 1-\mathrm{N} 3$ & $134.82(6)$ \\
\hline $\mathrm{O} 2-\mathrm{Zr} 1-\mathrm{N} 2$ & $69.64(6)$ & $\mathrm{N} 1-\mathrm{Zr} 1-\mathrm{N} 4$ & $126.13(7)$ \\
\hline $\mathrm{O} 2-\mathrm{Zr} 1-\mathrm{N} 3$ & $76.04(6)$ & $\mathrm{N} 2-\mathrm{Zr} 1-\mathrm{N} 3$ & $118.29(7)$ \\
\hline $\mathrm{O} 2-\mathrm{Zr} 1-\mathrm{N} 4$ & $74.45(7)$ & $\mathrm{N} 2-\mathrm{Zr} 1-\mathrm{N} 4$ & $136.13(7)$ \\
\hline $\mathrm{O} 3-\mathrm{Zr} 1-\mathrm{O} 4$ & $89.34(7)$ & $\mathrm{N} 3-\mathrm{Zr} 1-\mathrm{N} 4$ & $74.83(7)$ \\
\hline \multicolumn{4}{|l|}{$\beta-\mathrm{Zrq}_{4}$} \\
\hline $\mathrm{Zr1-O} 1$ & $2.113(2)$ & $\mathrm{Zr} 1-\mathrm{N} 1$ & $2.468(2)$ \\
\hline $\mathrm{Zr} 1-\mathrm{O} 2$ & $2.109(2)$ & $\mathrm{Zr1-N2}$ & $2.417(2)$ \\
\hline $\mathrm{Zr} 1-\mathrm{O} 3$ & $2.107(2)$ & Zr1-N3 & $2.443(2)$ \\
\hline $\mathrm{Zr} 1-\mathrm{O} 4$ & $2.1152(14)$ & Zr1-N4 & $2.413(2)$ \\
\hline $\mathrm{O} 1-\mathrm{Zr} 1-\mathrm{O} 2$ & $85.34(6)$ & $\mathrm{O} 3-\mathrm{Zr} 1-\mathrm{N} 1$ & $77.03(6)$ \\
\hline $\mathrm{O} 1-\mathrm{Zr} 1-\mathrm{O} 3$ & $113.95(6)$ & $\mathrm{O} 3-\mathrm{Zr} 1-\mathrm{N} 2$ & $75.75(6)$ \\
\hline $\mathrm{O} 1-\mathrm{Zr} 1-\mathrm{O} 4$ & 142.71(6) & $\mathrm{O} 3-\mathrm{Zr} 1-\mathrm{N} 3$ & $70.03(5)$ \\
\hline $\mathrm{O} 1-\mathrm{Zr} 1-\mathrm{N} 1$ & $69.39(6)$ & $\mathrm{O} 3-\mathrm{Zr} 1-\mathrm{N} 4$ & $139.28(6)$ \\
\hline $\mathrm{O} 1-\mathrm{Zr} 1-\mathrm{N} 2$ & $138.88(6)$ & $\mathrm{O} 4-\mathrm{Zr} 1-\mathrm{N} 1$ & $147.88(5)$ \\
\hline $\mathrm{O} 1-\mathrm{Zr} 1-\mathrm{N} 3$ & $77.89(6)$ & $\mathrm{O} 4-\mathrm{Zr} 1-\mathrm{N} 2$ & $75.32(6)$ \\
\hline $\mathrm{O} 1-\mathrm{Zr} 1-\mathrm{N} 4$ & 76.07(6) & $\mathrm{O} 4-\mathrm{Zr} 1-\mathrm{N} 3$ & $78.88(6)$ \\
\hline $\mathrm{O} 2-\mathrm{Zr} 1-\mathrm{O} 3$ & $143.19(6)$ & $\mathrm{O} 4-\mathrm{Zr} 1-\mathrm{N} 4$ & $69.79(6)$ \\
\hline $\mathrm{O} 2-\mathrm{Zr} 1-\mathrm{O} 4$ & $98.85(6)$ & $\mathrm{N} 1-\mathrm{Zr} 1-\mathrm{N} 2$ & $74.82(6)$ \\
\hline $\mathrm{O} 2-\mathrm{Zr} 1-\mathrm{N} 1$ & $81.69(6)$ & $\mathrm{N} 1-\mathrm{Zr} 1-\mathrm{N} 3$ & $117.69(6)$ \\
\hline $\mathrm{O} 2-\mathrm{Zr} 1-\mathrm{N} 2$ & $69.84(6)$ & $\mathrm{N} 1-\mathrm{Zr} 1-\mathrm{N} 4$ & $138.90(6)$ \\
\hline $\mathrm{O} 2-\mathrm{Zr} 1-\mathrm{N} 3$ & $146.73(6)$ & $\mathrm{N} 2-\mathrm{Zr} 1-\mathrm{N} 3$ & $138.65(5)$ \\
\hline $\mathrm{O} 2-\mathrm{Zr} 1-\mathrm{N} 4$ & $73.84(6)$ & $\mathrm{N} 2-\mathrm{Zr} 1-\mathrm{N} 4$ & $123.96(6)$ \\
\hline $\mathrm{O} 3-\mathrm{Zr} 1-\mathrm{O} 4$ & $84.43(6)$ & N3-Zr1-N4 & $74.32(6)$ \\
\hline \multicolumn{4}{|c|}{ Dihedral angles/degrees between $\mathrm{ZrNCCO}$ chelate rings } \\
\hline$\alpha-\mathrm{Zrq}_{4}$ & & & $\beta-\mathrm{Zrq}_{4}$ \\
\hline $26.95(9)$ & & & $23.21(8)$ \\
\hline 29.41(9) & & & $25.31(8)$ \\
\hline $77.59(9)$ & & & $68.63(8)$ \\
\hline $80.32(9)$ & & & $73.41(8)$ \\
\hline $84.96(9)$ & & & $78.58(8)$ \\
\hline $85.23(9)$ & & & $88.69(8)$ \\
\hline
\end{tabular}

We prepared $\mathrm{Zrq}_{4}$ from a range of solvents including ethanol, acetonitrile, phenyl cyanide, dichloromethane, toluene and THF by reacting $\mathrm{ZrCl}_{4}$ with hq. We found that ethanol gave the best yield of $93 \%$. The product from this method required Soxhlet extraction using dioxane to remove any traces of chlorine before sublimation, but the yield after soxhlet extraction was only $77 \%$. We refer to this product as $\beta-\mathrm{Zrq}_{4}$. For the fabrication of OLEDs, high purity materials (purity better than $99.95 \%$ ) are required which are free of chlorine (and certain trace metals such as $\mathrm{Cr}, \mathrm{Fe}, \mathrm{Co}, \mathrm{Ni}$ ). Thus, alternative synthetic methods were investigated and we found that the synthesis based on the starting material zirconium isopropoxide gave a high yield (88\%) of a very pure product which did not require Soxhlet extraction. The yield for the sublimation step was $91 \%$. We assigned the designation $\alpha-\mathrm{Zrq}_{4}$ to this product (Table 2).

\section{Crystal structures of $\alpha-Z_{r q}$ and $\beta-Z_{r q}$}

In both $\alpha-\mathrm{Zrq}_{4}$ and $\beta-\mathrm{Zrq}_{4}$ the metal centre is eight-coordinated by four chelating N,O pairs from four 8-hydroxyquinolinolate ligands (Fig. 1). The coordination by each pair is strongly asymmetric, with $\mathrm{Zr}-\mathrm{O}$ distances of around $2.1 \AA$ and $\mathrm{Zr}-\mathrm{N}$ distances of over $2.4 \AA$ (Table 3). The dihedral angles between the five-membered $\mathrm{ZrNCCO}$ chelate rings show similar but not identical patterns (please see Table S1 in the ESI $\dagger$ ), indicative of broadly similar overall geometry. As neither space group is symmorphic, both contain equal amounts of each enantiomer, and by selecting corresponding enantiomers from each phase it is possible to illustrate the fact that the molecular structures are indeed very similar (Fig. 1).

The extended structures of both forms feature extensive $\pi \cdots \pi$ and $\mathrm{C}-\mathrm{H} \cdots \pi$ interactions, but only the $\alpha$ form exhibits short $\mathrm{C}-\mathrm{H} \cdots \mathrm{O}$ contacts and short centroid-centroid distances between $\pi$ systems (Table S1 in the ESI $\dagger$ ). The higher density of the $\alpha$ form $\left(1.571 \mathrm{~g} \mathrm{~cm}^{-3}\right)$ compared to that of the $\beta$-form $(1.529 \mathrm{~g}$ $\mathrm{cm}^{-3}$ ) suggests that the former has more efficient packing (Fig. 2) and is therefore expected to be the more stable form. This was indeed confirmed by in situ q-mass spectroscopy where the $\alpha$ form was found to survive longer (no decomposition) than the $\beta-\mathrm{Zrq}_{4}$ on extended heating under OLED production conditions. ${ }^{29,30}$

Differential scanning calorimetry (Fig. 3) of $\alpha-\mathrm{Zrq}_{4}$ shows a pre-peak (i.e., a peak before the main melting point) whereas the $\beta-\mathrm{Zrq}_{4}$ form does not, providing a further distinction between the two forms. Such pre-peaks are usually observed for a variety of materials including metal complexes and polymers where there are both crystalline and amorphous components present or there are slight changes in the conformation of the molecules (twisting) ${ }^{38}$ We believe that the pre-peak here is due to the amorphous component of $\alpha-\mathrm{Zrq}_{4}$ crystallising on annealing (heating). Fig. 4 shows the absorption spectra as well as fluorescence spectra of vacuum evaporated thin films of $\alpha-\mathrm{Zrq}_{4}$ and $\beta$ - $\mathrm{rq}_{4}$. There are no differences in absorption maximum, but the absorption edge (band gap) is slightly different, $2.68 \pm 0.01 \mathrm{eV}$ for the $\alpha$ form and $2.73 \pm 0.01 \mathrm{eV}$ for the $\beta$ form (Table 4). The fluorescence maximum of thin films of $\alpha-\mathrm{Zrq}_{4}$ occurs at slightly longer wavelength $(523 \pm 1 \mathrm{~nm})$ than that for $\beta-\mathrm{Zrq}_{4}(518 \pm 1$ $\mathrm{nm}$ ): this is expected as the former has lower optical band gap in addition to losses due to energy transfer to the vibrational energy 


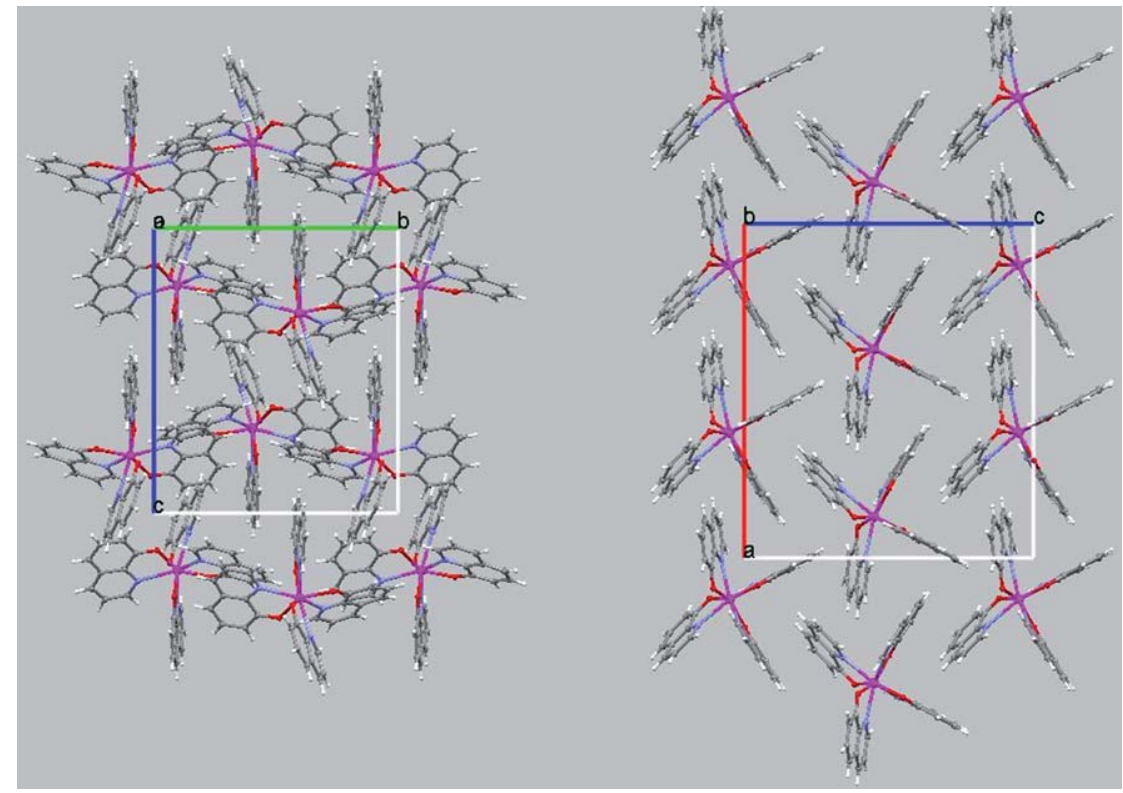

Fig. 2 Crystal packing arrangements in $\alpha-\mathrm{Zrq}_{4}$ and $\beta-Z \mathrm{Zq}_{4}$.

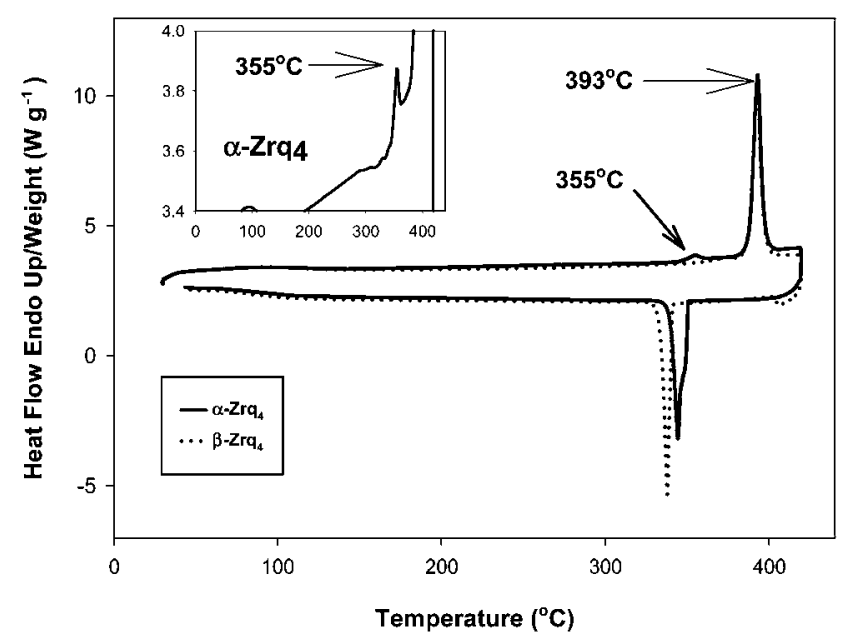

Fig. 3 Differential scanning calorimetry of $\alpha-\mathrm{Zrq}_{4}$ and $\beta-\mathrm{Zrq}_{4}$, scan rate at $30{ }^{\circ} \mathrm{C}$ per minute under nitrogen atmosphere.

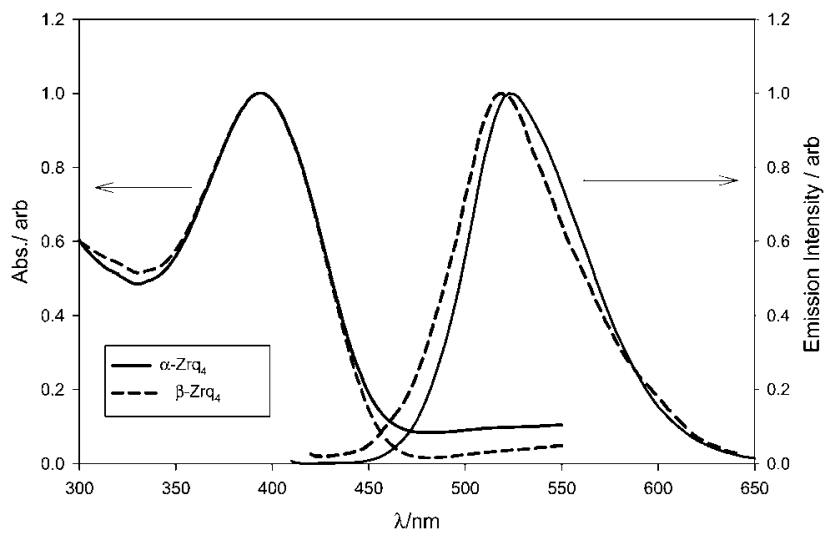

Fig. 4 Absorption and emission spectra of thin films: $\alpha-\mathrm{Zrq}_{4}$ and $\beta-\mathrm{Zrq}_{4}$. levels (the band gap is not discrete in molecular solids). The fluorescence band gap is correspondingly lower for $\alpha-Z_{r_{4}}(2.37$ $\mathrm{eV})$ than for $\beta-\mathrm{Zrq}_{4}(2.39 \mathrm{eV})$. However, the excited state of $\beta$ $\mathrm{Zrq}_{4}$ is more stabilised $(0.37 \mathrm{eV}$ below the LUMO level) as opposed to that of $\alpha-\mathrm{Zrq}_{4}(0.31 \mathrm{eV})$. The difference in the FWHM of the fluorescence spectra of the two forms indicates that the excited states of the two forms are different as expected.

The absorption and emission spectra of toluene solutions of the $\alpha-\mathrm{Zrq}_{4}$ and $\beta-\mathrm{Zrq}_{4}$ forms were identical.

Cyclic voltammetry $(\mathrm{CV})$ was performed in acetonitrile solvent containing the analyte $\left(\alpha-\mathrm{Zrq}_{4}\right.$ or $\left.\beta-\mathrm{Zrq}_{4}, 0.5 \mathrm{mM}\right)$ and supporting electrolyte (tetrabutyl ammonium tetrafluoroborate (10 $\mathrm{mM})$. The working, reference and secondary electrodes were $\mathrm{Pt}$ foil $\left(2 \mathrm{~cm}^{2}\right), \mathrm{Ag} / \mathrm{AgCl}$ and $\mathrm{Pt}$ wire, respectively.

The CV's were performed in both oxidation $(0$ to $+2.0 \mathrm{~V})$ and reduction $(0$ to $-1.9 \mathrm{~V})$ regions at various scan rates. Repetitive cyclic voltammograms were also performed in both the regions. The cyclic voltammetry in the oxidative region $(0$ to $+2.0 \mathrm{~V})$ was found to be irreversible whereas in the reductive region $(0$ to -1.9 V), it was quasi-reversible. ${ }^{32}$ The anodic peak current in the oxidative region was found to decrease with repetitive cycling owing to deposition of an insulating layer (brown coloration was also discernible at the electrode). However, the cathodic and anodic peaks in the reduction region were very reproducible (Fig. 5-7), the main cathodic peak being diffusion controlled $\left(i_{\mathrm{p}}\right.$ proportional to $r^{1 / 2}$ ) and the small peak seen around $-1.6 \mathrm{~V} v s$. $\mathrm{Ag} / \mathrm{AgCl}$ for $\alpha-\mathrm{Zrq}_{4}$ was confirmed to be an adsorption pre-wave $\left(i_{\mathrm{p}}\right.$ proportional to $r$ ) and not a redox peak. ${ }^{39}$ It is interesting to note that only the $\alpha$ form shows the adsorption pre-wave whereas the $\beta$ form does not. We then used the reduction region to work out the LUMO level of the compounds under study in this paper. The LUMO levels were determined from the equation in ref. 33:

$$
\mathrm{HOMO} \text { or } \mathrm{LUMO}=-\left(E_{1 / 2} \text { vs. } \mathrm{NHE}+4.40\right) \mathrm{eV}
$$

(NHE: Normal Hydrogen Electrode). 
Table 4 Thermal and optical properties of $\alpha-\mathrm{Zrq}_{4}$ and $\beta-\mathrm{Zrq}_{4}$

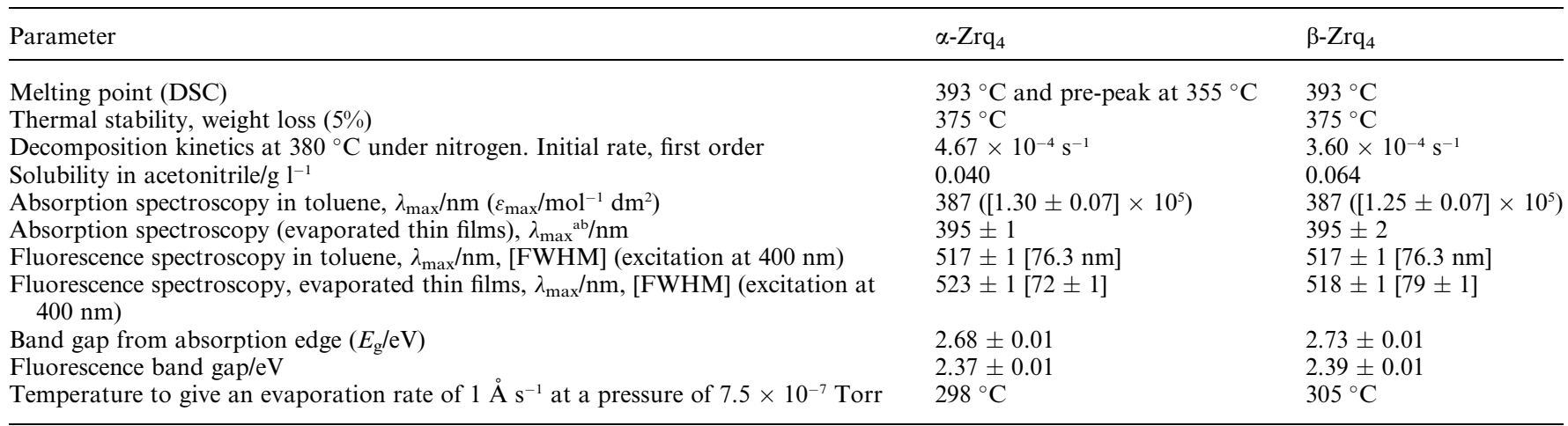

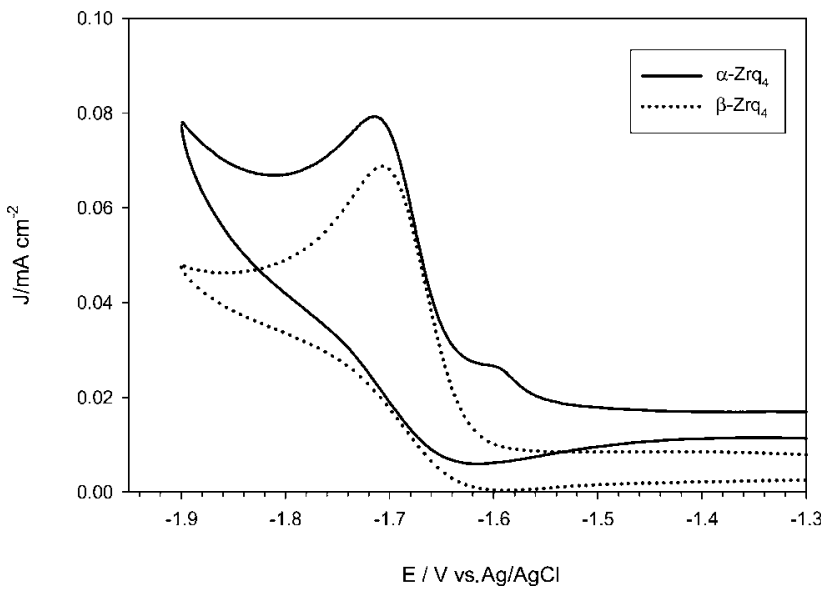

Fig. 5 Cyclic voltammetry; analyte $0.5 \mathrm{mM}$, supporting electrolyte (tetrabutyl ammonium tetrafluoroborate, $10 \mathrm{mM}$ ), solvent: acetonitrile, scan rate: $10 \mathrm{mV} \mathrm{S}^{-1}$, working electrode: Pt foil. Reference electrode: $\mathrm{Ag}$ / $\mathrm{AgCl}$.

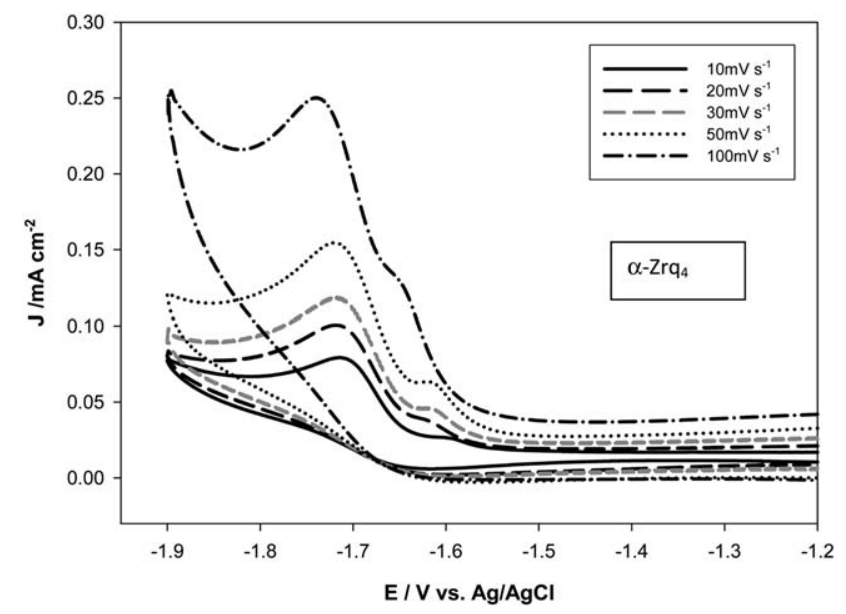

Fig. 6 Cyclic voltammetry: $\alpha-\mathrm{Zrq}_{4}$; different scan rates, analyte $0.5 \mathrm{mM}$, supporting electrolyte (tetrabutyl ammonium tetrafluoroborate, $10 \mathrm{mM}$ ), solvent: acetonitrile, working electrode: $\mathrm{Pt}$ foil. Reference electrode: $\mathrm{Ag} /$ $\mathrm{AgCl}$.

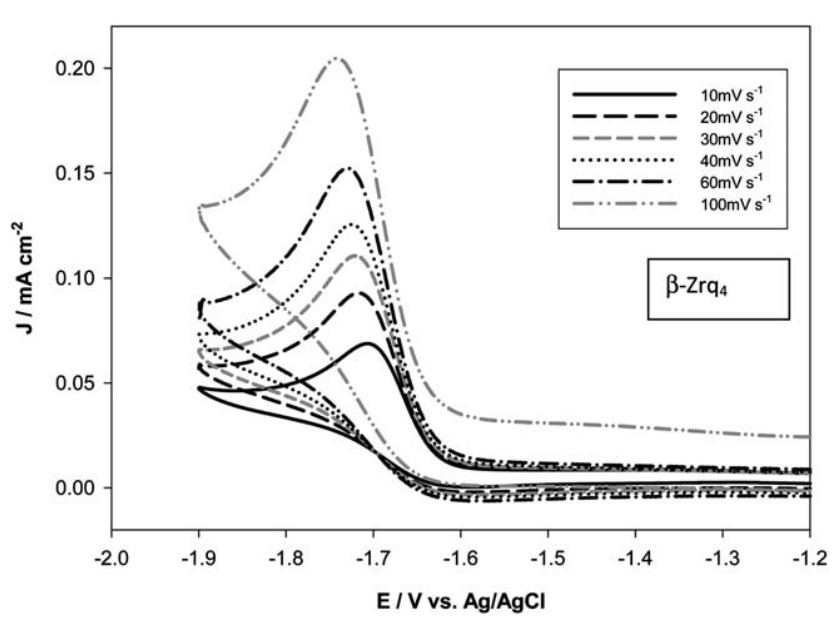

Fig. 7 Cyclic voltammetry: $\beta-Z \mathrm{rq}_{4}$; different scan rates, analyte $0.5 \mathrm{mM}$, supporting electrolyte (tetrabutyl ammonium tetrafluoroborate, $10 \mathrm{mM}$ ), solvent: acetonitrile, working electrode: Pt foil. Reference electrode: $\mathrm{Ag}$ / $\mathrm{AgCl}$.

Table 5 HOMO-LUMO levels of the two forms of $\mathrm{Zrq}_{4}$

\begin{tabular}{lll}
\hline Material & $\mathrm{LUMO} / \mathrm{eV}$ & $\mathrm{HOMO} / \mathrm{eV}$ \\
\hline$\alpha-\mathrm{Zrq}_{4}$ (from cyclic voltammetry) & $-2.94 \pm 0.02$ & $-5.62 \pm 0.02$ \\
$\alpha-\mathrm{Zrq}_{4}$ (photoelectron & -2.90 & -5.60 \\
spectroscopy), measured by Dr & & \\
T. Yuki, Pioneer, Japan & & \\
$\beta-Z \mathrm{Zrq}_{4}$ (from cyclic voltammetry) & $-2.94 \pm 0.02$ & $-5.70 \pm 0.02$ \\
$\mathrm{Alq}_{3}$ (from cyclic voltammetry) & $-2.90 \pm 0.02$ & $-5.70 \pm 0.02$ \\
\hline
\end{tabular}

Fig. 8 Electron only device, HOMO-LUMO values of $\alpha-Z r q 4, \beta-Z \mathrm{Zrq}_{4}$, $\mathrm{Alq}_{3}, \mathrm{Mg}: \mathrm{Al}$ alloy was used as the low work function electrode. 


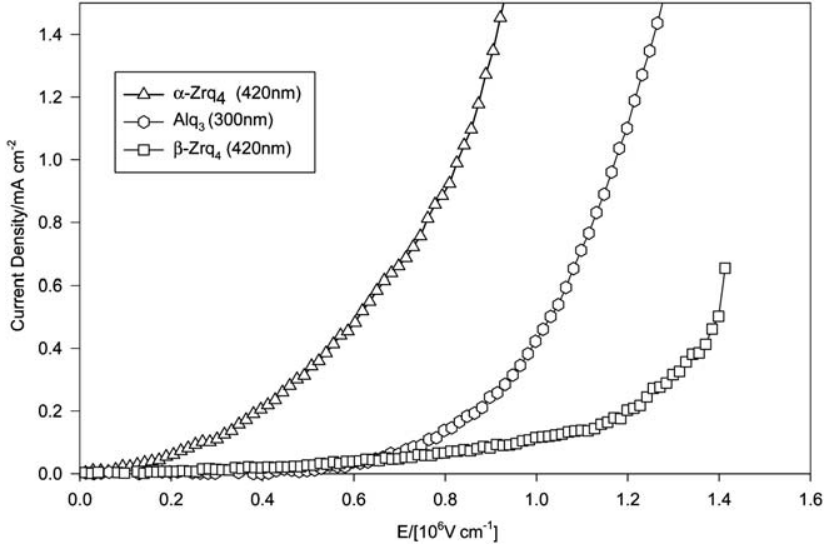

Fig. 9 Electron only devices, current density $\left(\mathrm{mA} \mathrm{cm}^{-2}\right) v$. field $\left(\mathrm{V} \mathrm{cm}^{-1}\right)$, (a) ITO/Mg : Al alloy/ $\alpha-\mathrm{Zrq}_{4}(420 \mathrm{~nm}) / \mathrm{Mg}$ : Al alloy; (b) ITO/Mg : Al/ $\beta-$ $\mathrm{Zrq}_{4}(420 \mathrm{~nm}) / \mathrm{Mg}: \mathrm{Al}$; (c) ITO/Mg: Al/Alq $(300 \mathrm{~nm}) / \mathrm{Mg}: \mathrm{Al}$.

The $E_{1 / 2}$ employed here were determined from the derivative of the cyclic voltammograms.

The cathodic peaks and its derivative of $\alpha-\mathrm{Zrq}_{4}$ were identical to those of $\beta-\mathrm{Zrq}_{4}$. Using the optical band gap from the absorption edge, the corresponding HOMO levels were then determined. The values are given in Table 5.

The electrical conductivity of the powders was measured as compacted discs using a two probe method. ${ }^{34}$ The electrical conductivities of compacted discs of $\alpha-\mathrm{Zrq}_{4}, \beta-\mathrm{Zrq}_{4}$ and $\mathrm{Alq}_{3}$ were found to be $5.8 \times 10^{-13}, 3.0 \times 10^{-13}$ and $5.0 \times 10^{-13} \mathrm{~S} \mathrm{~cm}^{-1}$, respectively.

Electron only devices (Fig. 8) of the configuration (ITO/Mg, $\mathrm{Al}$ alloy/Zrq $4(420 \mathrm{~nm})$ or $\mathrm{Alq}_{3}(300 \mathrm{~nm}) / \mathrm{Mg}, \mathrm{Al}$ alloy), fabricated by vacuum thermal evaporation, exhibited non-linear current density vs. field behaviour as shown in Fig. 9. We fitted these data for diode, tunnelling (Fowler Nordheim) and SCLC models. ${ }^{30-32,37}$ The data fitted the SCLC model but not the others.

Electron only devices (Fig. 8) show that the electron injection (Fig. 9) follows the order $\alpha-\mathrm{Zrq}_{4}>\mathrm{Alq}_{3}>\beta-\mathrm{Zrq}_{4}$. The current density $\left(J_{\mathrm{d}}\right) v s$. voltage $(V)$ plots were found to satisfy the SCLC model. From the ohmic region $\left(J_{\mathrm{d}}\right.$ proportional to $\left.V\right)$ and the space charge region $\left(J_{\mathrm{d}}\right.$ proportional to $\left.\mathrm{V}^{2}\right)$, conductivity and mobility values were determined. The conductivity of thin films of $\alpha-\mathrm{Zrq}_{4}, \beta-\mathrm{Zrq}_{4}$ and $\mathrm{Alq}_{3}$ were found to be $5.3 \times 10^{-10}, 1.3 \times$ $10^{-13}$ and $1.9 \times 10^{-11} \mathrm{~S} \mathrm{~cm}^{-1}$, respectively, and the mobility values were estimated to be $1.7 \times 10^{-7}, 1.6 \times 10^{-8}$ and $1.3 \times 10^{-7}$ $\mathrm{cm}^{2} \mathrm{~V}^{-1} \mathrm{~s}^{1}$, respectively, using the equation:

$$
J_{\mathrm{SCLC}}=(9 / 8) \varepsilon \mu V^{2} / d^{3}
$$

where $J_{\mathrm{SCLC}}=$ current density in the SCLC region, $\varepsilon=$ permittivity, $\mu=$ mobility, $V=$ voltage and $d=$ thickness.

The conductivity, mobility, charge carrier density and the permittivity of the two forms of $\mathrm{Zrq}_{4}$ are compared with $\mathrm{Alq}_{3}$ in Table 6. The permittivity of $\mathrm{Alq}_{3}$ was found to be $3.06 \pm 0.1$ which is comparable to the value of 3.15 reported in ref. 30 .

The mobility value measured in this work for $\mathrm{Alq}_{3}$ is comparable to the previously published value of $5 \times 10^{-7} \mathrm{~cm}^{2} \mathrm{~V}^{-1} \mathrm{~s}^{-1}$. 35 These data are summarised in Table 6. There is a substantial difference in conductivities between the compacted discs of the powders and the amorphous films produced by vacuum thermal evaporation which is possibly due to the morphology and the nature of packing.

$\alpha-\mathrm{Zrq}_{4}$ has nearly ten fold higher mobility and $4 \times 10^{3}$ fold higher conductivity than $\beta-\mathrm{Zrq}_{4}$. We wanted to establish how

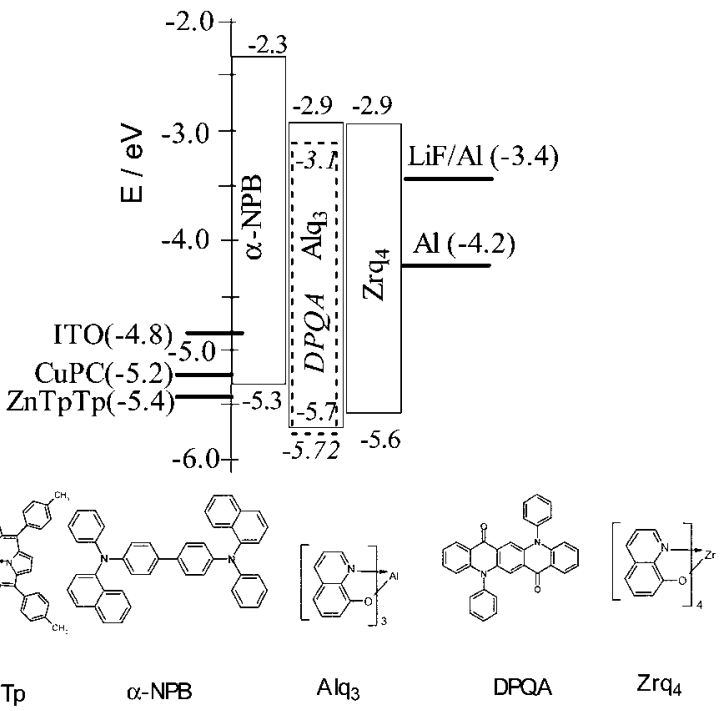

Fig. 10 HOMO-LUMO energy levels for ZnTpTp (hole injector), $\alpha$ NPB (hole transporter), $\mathrm{Alq}_{3}$ (Host), DPQA (---green dopant), $\mathrm{Zrq}_{4}$ (electron transporter).

Table 6 Comparison of electrical and electronic properties of $\alpha-\mathrm{Zrq}_{4}$ and $\beta-\mathrm{Zrq}_{4}$ with $\mathrm{Alq}_{3}$

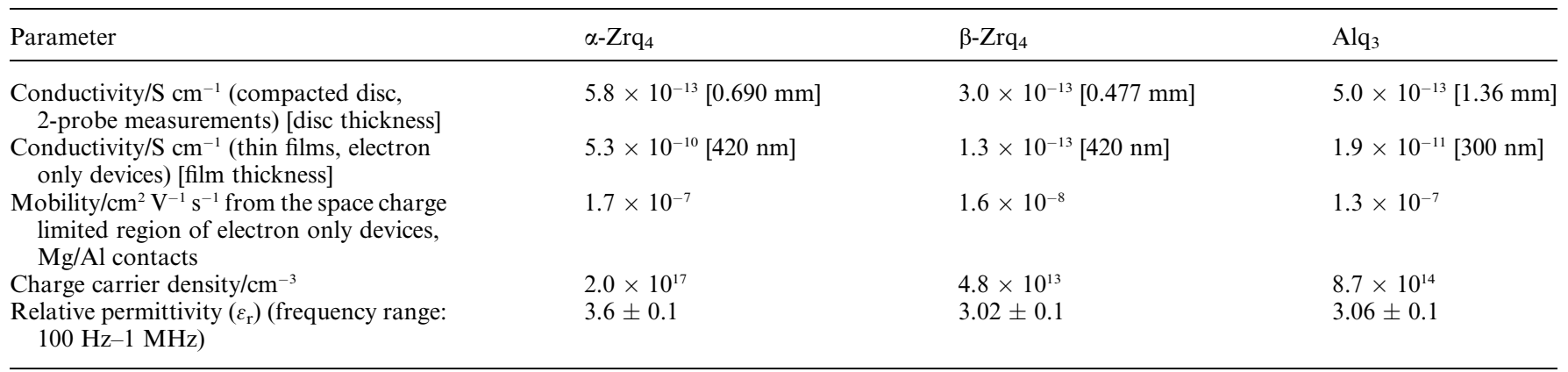




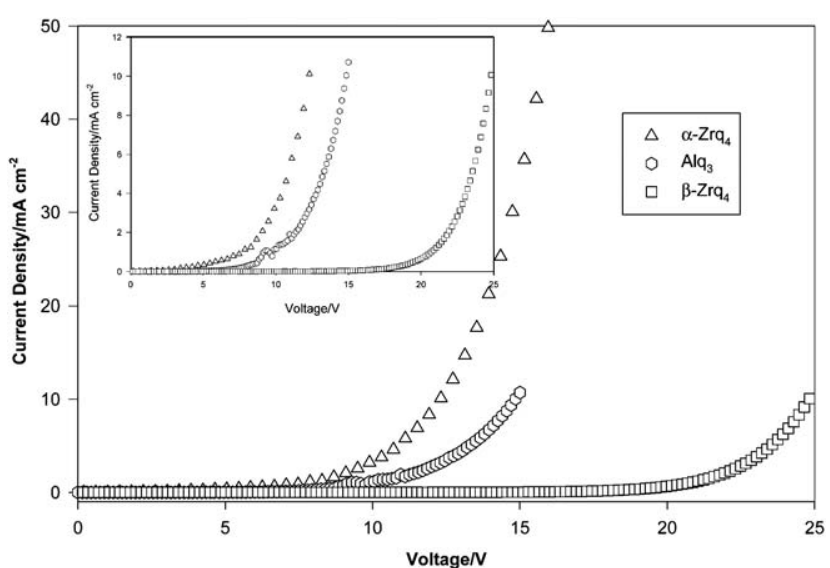

Fig. 11 Current density $\left(\mathrm{mA} \mathrm{cm} \mathrm{cm}^{-2}\right)$ vs. voltage (V). Device, ITO/ $\mathrm{ZnTpTp}(50 \mathrm{~nm}) / \alpha-\mathrm{NPB}(50 \mathrm{~nm}) / \mathrm{Alq}_{3}: \operatorname{DPQA}(50: 0.1 \mathrm{~nm}) / \mathrm{ETL}(20 \mathrm{~nm}) /$ $\mathrm{LiF}(0.5 \mathrm{~nm}) / \mathrm{Al}$, where ETL is $\alpha-\mathrm{Zrq}_{4}, \beta-\mathrm{Zrq}_{4}$ or $\mathrm{Alq}_{3}$.

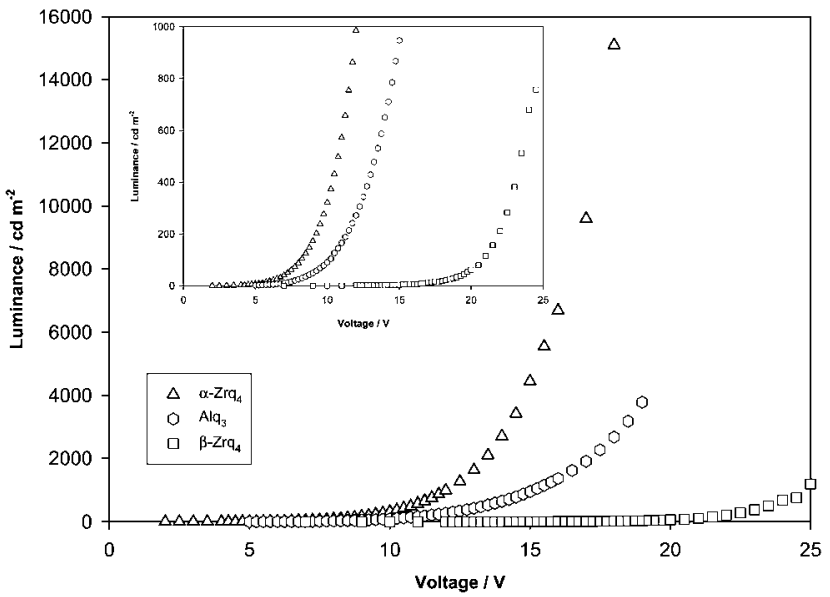

Fig. 12 Luminance $\left(\mathrm{cd} \mathrm{m}^{-2}\right)$ vs. voltage $(\mathrm{V})$; device, ITO/ZnTpTp $(50$ $\mathrm{nm}) / \alpha-\mathrm{NPB}(50 \mathrm{~nm}) / \mathrm{Alq}_{3}: \operatorname{DPQA}(50: 0.1 \mathrm{~nm}) / \mathrm{ETL}(20 \mathrm{~nm}) / \mathrm{LiF}(0.5 \mathrm{~nm}) /$ $\mathrm{Al}$, where ETL is $\alpha-\mathrm{Zrq}_{4}, \beta-\mathrm{Zrq}_{4}$ or $\mathrm{Alq}_{3}$.

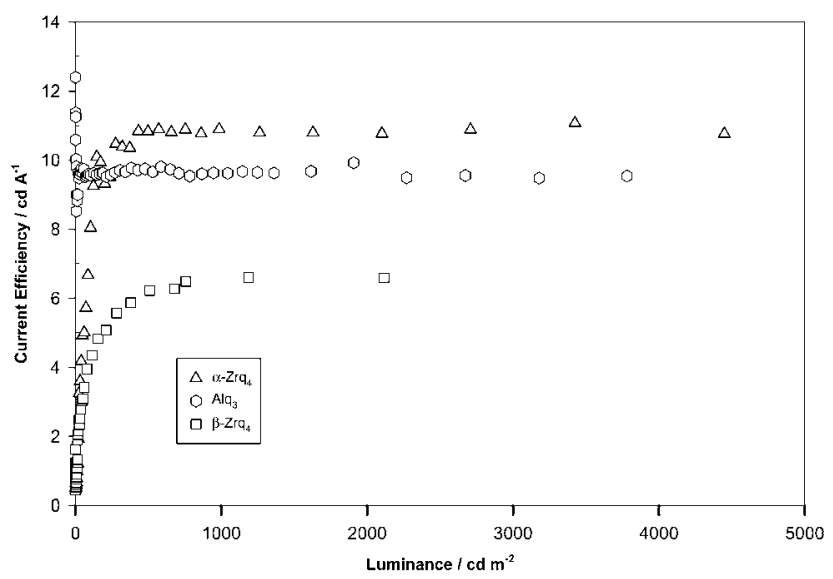

Fig. 13 Current efficiency $\left(\mathrm{cd} \mathrm{A}^{-1}\right) v s$. luminance $\left(\mathrm{cd} \mathrm{m}^{-2}\right)$ characteristics. Device, ITO/ZnTpTp $(50 \mathrm{~nm}) / \alpha-\mathrm{NPB}(50 \mathrm{~nm}) / \mathrm{Alq}_{3}: \operatorname{DPQA}(50: 0.1$ $\mathrm{nm}) / \operatorname{ETL}(20 \mathrm{~nm}) / \mathrm{LiF}(0.5 \mathrm{~nm}) / \mathrm{Al}$, where ETL is $\alpha-\mathrm{Zrq}_{4}, \beta-\mathrm{Zrq}_{4}$ or $\mathrm{Alq}_{3}$.

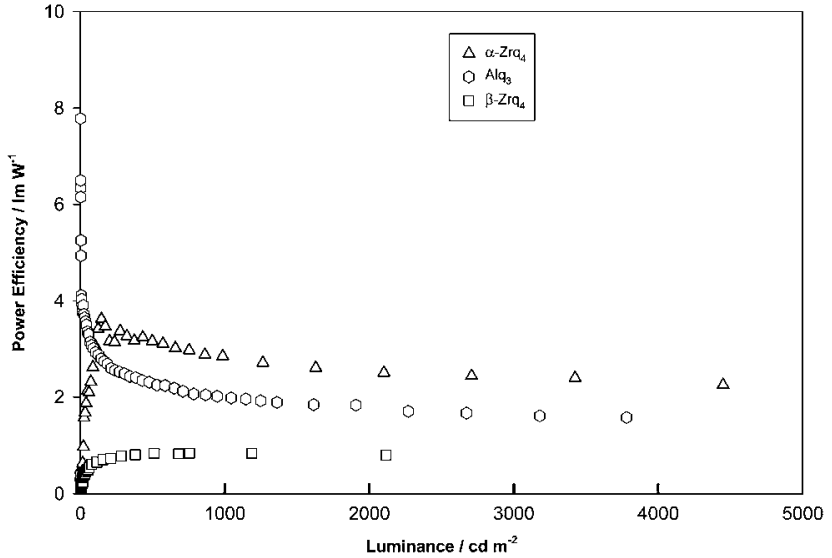

Fig. 14 Power efficiency $\left(\mathrm{lm} \mathrm{W}^{-1}\right) v s$. luminance $\left(\mathrm{cd} \mathrm{m}^{-2}\right)$. device, ITO/ $\mathrm{ZnTpTp}(50 \mathrm{~nm}) / \alpha-\mathrm{NPB}(50 \mathrm{~nm}) / \mathrm{Alq}_{3}: \operatorname{DPQA}(50: 0.1 \mathrm{~nm}) / \mathrm{ETL}(20 \mathrm{~nm}) /$ $\mathrm{LiF}(0.5 \mathrm{~nm}) / \mathrm{Al}$, where ETL is $\alpha-\mathrm{Zrq}_{4}, \beta-\mathrm{Zrq}_{4}$, or $\mathrm{Alq}_{3}$.

much influence this would have on the performance of light emitting devices (OLEDs).

\section{Device performance}

We fabricated green OLEDs having the structure: glass/ITO/ $\mathrm{ZnTPTP}(50 \mathrm{~nm}) / \alpha-\mathrm{NPB}(50 \mathrm{~nm}) / \mathrm{Alq}_{3}: \mathrm{DPQA}(50 \mathrm{~nm}: 0.1 \mathrm{~nm}) /$ $\operatorname{ETL}(20 \mathrm{~nm}) / \mathrm{LiF}(0.5 \mathrm{~nm}) / \mathrm{Al}$ where ETL is $\mathrm{Alq}_{3}, \alpha-\mathrm{Zrq}_{4}$ or $\beta$ $\mathrm{Zrq}_{4}$ using the Solciet OLED Pilot Plant equipment. The energy level diagram for this device structure under zero bias is depicted in Fig. 10.

The current density $\left(J_{\mathrm{d}}\right) v s$. voltage $(V)$, luminance $\left(\mathrm{cd} \mathrm{m}^{-2}\right) v s$. voltage $(V)$, current efficiency $\left(\mathrm{cd} \mathrm{A}^{-1}\right)$ vs. luminance and power efficiency $\left(\mathrm{lm} \mathrm{W}^{-1}\right)$ vs. luminance are shown in Fig. 11-14.

The current density $v s$. voltage plot very clearly shows that the current injection and transport from the $\alpha-Z_{r q}$ is the highest followed by $\mathrm{Alq}_{3}$ and then $\beta-\mathrm{Zrq}_{4}$ (i.e., $\alpha-\mathrm{Zrq}_{4}>\mathrm{Alq}_{3}>\beta-\mathrm{Zrq}_{4}$ ), simply following the order of the electron mobility and film conductivity, consistent with our findings on the electron only devices.

Similarly, luminance $v s$. voltage plot shows that the operating voltage for any given luminance is also lowest for the $\alpha$-form (i.e., the order is $\left.\alpha-\mathrm{Zrq}_{4}<\mathrm{Alq}_{3}<\beta-\mathrm{Zrq}_{4}\right)$. The current efficiency $v$. luminance and power efficiency vs. luminance follow the same order as the electron mobility $\left(\alpha-\mathrm{Zrq}_{4}>\mathrm{Alq}_{3}>\beta-\mathrm{Zrq}_{4}\right)$, as shown in Table 6 .

The current efficiency at $1000 \mathrm{~cd} \mathrm{~m}^{-2}$ for $\alpha-\mathrm{Zrq}_{4}$ devices is $11 \mathrm{~cd}$ $\mathrm{A}^{-1}$ as opposed to $6.5 \mathrm{~cd} \mathrm{~A}{ }^{-1}$ for the $\beta-\mathrm{Zrq}_{4}$ based devices (Table 7). The power efficiency of the devices from the $\alpha$-form $(3 \mathrm{~lm}$ $\left.\mathrm{W}^{-1}\right)$ is three times as high as that from the $\beta$-form $\left(1 \mathrm{~lm} \mathrm{~W} \mathrm{~W}^{-1}\right)$ at $1000 \mathrm{~cd} \mathrm{~m}^{-2}$. The turn-on voltage of $\alpha-\mathrm{Zrq}_{4}(2.5 \mathrm{~V})$ is half that for identical devices with $\mathrm{Alq}_{3}(5.0 \mathrm{~V})$, while that of $\beta-\mathrm{Zrq}_{4}(7.0 \mathrm{~V})$ is $2 \mathrm{~V}$ higher than that of $\mathrm{Alq}_{3}$ based devices. We attribute this to the high conductivity, mobility and charge carrier density of $\alpha$ $\mathrm{Zrq}_{4}$ compared to the $\beta-\mathrm{Zrq}_{4}$.

This difference is significant and indicates the remarkable influence of the different phases and the importance in selecting the appropriate form (phase) of the complex to achieve good results.

The device characteristics are summarised in Table 7. 
Table 7 Device performance summary for ITO/ZnTPTP $(50 \mathrm{~nm}) / \alpha-\mathrm{NPB}(50 \mathrm{~nm}) / \mathrm{Alq}_{3}: \mathrm{DPQA}(50 \mathrm{~nm}: 0.1 \mathrm{~nm}) / \mathrm{ETL}(20 \mathrm{~nm}) / \mathrm{LiF}(0.5 \mathrm{~nm}) / \mathrm{Al}$

\begin{tabular}{|c|c|c|c|}
\hline Parameter & $\mathrm{ETL}-\mathrm{Alq}_{3}$ & $\mathrm{ETL}-\alpha-\mathrm{Zrq}_{4}$ & $\mathrm{ETL}-\beta-\mathrm{Zrq}_{4}$ \\
\hline $\begin{array}{l}\text { Turn-on voltage }\left(V_{t} / V\right) \text { measured at } \\
1 \mathrm{~cd} \mathrm{~m}^{-2}\end{array}$ & 5.0 & 2.5 & 7.0 \\
\hline$V$ at $1000 \mathrm{~cd} \mathrm{~m}^{-2}$ & 12.5 & 10.0 & 24.0 \\
\hline $\begin{array}{l}\text { Current efficiency/cd } \mathrm{A}^{-1} \text { at } 1000 \mathrm{~cd} \\
\mathrm{~m}^{-2}\end{array}$ & 9.5 & 11.0 & 6.5 \\
\hline Power efficiency at $1000 \mathrm{~cd} \mathrm{~m}^{-2}$ & 2.0 & 3.0 & 1.0 \\
\hline $\begin{array}{l}\text { Half-life at } 1200 \mathrm{~cd} \mathrm{~m}^{-2} \text { (for } 50 \% \\
\text { reduction), }\left(t_{0.5} / \mathrm{h}\right) \text {, extrapolated. }\end{array}$ & 8000 & 50000 & $\begin{array}{l}\text { Not monitored because of its high } \\
\text { operating voltage }\end{array}$ \\
\hline
\end{tabular}

Table 8 Summary of voltage ranges for Ohmic and SCL regions

\begin{tabular}{llll}
\hline Device & $\begin{array}{l}\text { Ohmic region } \\
\left(J_{\mathrm{d}} \propto V\right)\end{array}$ & $\begin{array}{l}\text { SCLC region } \\
\left(J_{\mathrm{d}} \propto V^{2}\right)\end{array}$ & $\begin{array}{l}\text { Maximum } m \text { value } \\
\left(J_{\mathrm{d}} \propto V^{m+1}\right)\end{array}$ \\
\hline$\alpha-\mathrm{Zrq}_{4}$ & $0<V<1 \mathrm{~V}$ & $1<V<7 \mathrm{~V}$ & 5.4 \\
$\mathrm{Alq}_{3}$ & $0<V<1 \mathrm{~V}$ & $1<V<3 \mathrm{~V}$ & 4.9 \\
$\beta-\mathrm{Zrq}_{4}$ & $0<V<2 \mathrm{~V}$ & $2<V<10$ & 11.8 \\
\hline
\end{tabular}

\section{Mechanism of carrier injection}

The current density $v s$. voltage plots for $\alpha-\mathrm{Zrq}_{4}, \beta-\mathrm{Zrq}_{4}$ and $\mathrm{Alq}_{3}$ devices are shown in Fig. 11. $J_{\mathrm{d}} v s$. $V$ were fitted to normal diode, tunnelling (Fowler Nordheim) and SCLC models ${ }^{35-37}$ and we found that all the data fitted the SCLC model. None of the data fitted diode or tunnelling models. At very low voltages, the current varies linearly with voltage (ohmic relationship) and at intermediate voltages, the current becomes proportional to $V^{2}$ (Child's Law, Table 8). At high fields, the current increases proportionately with $V^{\mathrm{m}+1}$ according to the equation:

$$
J_{\mathrm{d}}=A V^{m+1} / d^{(2 m+1)} \text { where } A \text { is a constant. }
$$

The fact that the current continues to increase with $V^{n}$ indicates that there is a distribution of traps within the band gap of the material. The substantial differences in the $m$ values between

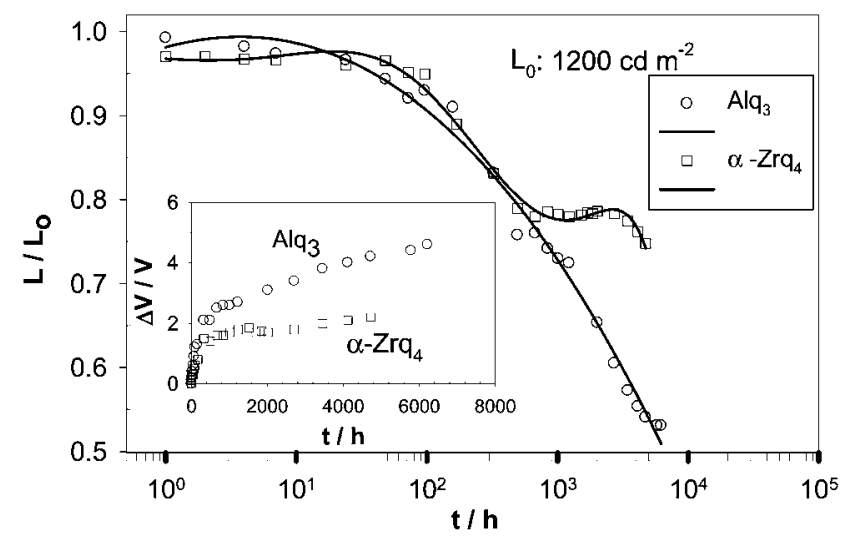

Fig. 15 Lifetime plots of Alq3, $\alpha-\mathrm{Zrq}_{4}$ for device, ITO/ZnTpTp $(50 \mathrm{~nm}) /$ $\alpha-\mathrm{NPB}(50 \mathrm{~nm}) / \mathrm{Alq} 3+\mathrm{DPQA}(50+0.1 \mathrm{~nm}) / \mathrm{Zrq}_{4}(20 \mathrm{~nm}) / \mathrm{LiF}(0.5 \mathrm{~nm}) / \mathrm{Al}$. Inset, drift voltage plot of $\alpha-\mathrm{Zrq}_{4}$; and $\mathrm{Alq}_{3} ; \Delta V=\left(V_{t}-V_{\mathrm{o}}\right) / V_{\mathrm{o}}$. the $\alpha$ and the $\beta$ form indicate that the distribution of traps within the layers is different, as expected from the different crystallographic forms which would be present even in amorphous films.

The lifetime measurements (Fig. 15) were carried out on $\alpha-\mathrm{Zrq}_{4}$ and $\mathrm{Alq}_{3}$ devices at an initial luminance of $1200 \mathrm{~cd} \mathrm{~m}^{-2}$ under constant current driving. The luminance $v s$. time plots show that $\alpha-\mathrm{Zrq}_{4}$ has a longer lifetime than $\mathrm{Alq}_{3}$. Because the devices based on the $\beta-\mathrm{Zrq}_{4}$ required too high a voltage, the lifetime measurements on these devices were not performed. The lifetime $\left(t_{0.7}\right)$ for the luminance from $1200 \mathrm{~cd} \mathrm{~m}^{-2}$ to $840 \mathrm{~cd}$ $\mathrm{m}^{-2}$ is 1500 hours for $\mathrm{Alq}_{3}$ based devices as opposed to 5000 hours for $\alpha-\mathrm{Zrq}_{4}$ and the extrapolated half-life values are 8000 hours and 50000 hours, respectively. This remarkable enhancement in lifetime is attributed to the stability of $\alpha-\mathrm{Zrq}_{4}$, in particular to holes. The luminance decay of $\alpha-\mathrm{Zrq}_{4}$ devices takes place in two stages unlike $\mathrm{Alq}_{3}$ based devices. This is currently under investigation.

Drift voltage versus time $\left[V_{t}\right.$ (voltage at time, $\left.t\right)-V_{0}$ (voltage at time, 0$)] / V_{0}$ plots show that $\alpha-\mathrm{Zrq}_{4}$ has lower drift voltage than $\mathrm{Alq}_{3}$ based devices, indicating that $\mathrm{Zrq}_{4}$ is not prone to degradation to holes, in contrast to $\mathrm{Alq}_{3}$. Low drift voltage is very important for stable operation of displays as otherwise an expensive compensation mechanism has to be built into the electronic drivers of the displays.

In this paper, we have compared the performance of fluorescent green OLED devices with $\alpha-\mathrm{Zrq}_{4}$ and $\mathrm{Alq}_{3}$ as electron transporters where the former shows superior behaviour: however, the same has been found to be true for red (both fluorescent and phosphorescent), green (phosphorescent) and blue (both fluorescent and phosphorescent) emitting OLEDs. These results will be published elsewhere.

\section{Conclusions}

Differences in the characteristics of the devices constructed from $\alpha-\mathrm{Zrq}_{4}$ and $\beta-\mathrm{Zrq}_{4}$, prepared from zirconium isopropoxide and zirconium chloride, respectively, have been explained on the basis of their differences in crystal structure (and therefore morphology), mobility and conductivity. Surprisingly, the difference in the HOMO-LUMO levels of the two forms is very small. This paper illustrates the importance of establishing the possibility of existence of different phases of metal complexes before discounting them as unsuitable for device applications, 
particularly in OLEDs. Surprisingly, one form does not convert into another under normal sublimation conditions.

The two forms show substantial differences in electrical and electronic properties. The $\alpha$-form was found to be superior to $\mathrm{Alq}_{3}$ in electron transport and lifetime while the $\beta$-form was inferior to $\mathrm{Alq}_{3}$, clearly indicating the need for further studies of other metal complexes used as electron transporters as to the existence of different forms (phases). Our results raise the obvious question of whether there are any more phases of $\mathrm{Zrq}_{4}$. Further studies of $\mathrm{Zrq}_{4}$ as electron transporters with other blue and red emitting devices will be reported elsewhere. Preliminary studies on $\mathrm{Hfq}_{4}$ (HOMO: $-5.7 \mathrm{eV}$, LUMO: $-3.0 \mathrm{eV}$ ) show poorer performance than for $\alpha-\mathrm{Zrq}_{4}$. It would be interesting to investigate the possibility of different phases of $\mathrm{Hfq}_{4}$.

The superior quality of $\alpha-\mathrm{Zrq}_{4}$ has led a number of display manufacturers to choose this material over $\mathrm{Alq}_{3}$ as an electron transporter.

\section{Acknowledgements}

We thank Dr T. Yuki and his colleagues at Pioneer, Japan, Dr C. Domoto and his colleagues at Kyocera, Japan and Dr H. C. Lee and his colleagues at Samsung, Korea, Dr Y. Oh of LG Displays (Korea) and Dr J. J. Lee of AUO, Taiwan for many stimulating discussions. We also thank the Professors C. Jenks, M. Sarhadi, G. Rodgers and J. Silver (all of Brunel University) and Dr D. R. Rosseinsky (Exeter) for encouragement. We thank EPSRC for funding of a diffractometer.

\section{References}

1 P. Kathirgamanathan, V. Arkley, S. Surendrakumar, G. Paramaswara, J. Antipán-Lara, S. Ravichandran, S. Ganeshamurugan, M. Kumaraverl and Y. F. Chan, Asian Society For Information Display, 2007, ISBN: 978-981-05-8143-5.

2 K. Ueno, A. Senoo and S. Mashmo, US Pat., 6436559B1, 20-08-2002.

3 S. H. Son, O. K. Kim, S. H. Yoon, K. K. Kim., Y. G. Lee and J. S. Bae, US Pat., 6720573B2, 13-04-2004.

4 K. P. Klubeck and D. Y. Kondakov, US Pat., 2007/0122657, 31-052007.

5 P. Kathirgamanathan, V. Kandappu, S. Hara, K. Chandrakumar, S. L. Marianesan, S. Selvaranjan, S. Surendrakumar and M. J. Toohey, Mater. Lett., 1999, 40, 285.

6 S. Reinnke, F. Lindner, G. Schwartz, N. Seidler, K. Walzer, B. Lussem and K. Leo, Nature, 2009, 459, 234.

7 H. Sasabe, T. Chiba, S. J. Su, Y.-J. Pu, K. Naayama and J. Kido, Chem. Commun., 2008, 5821.

8 J. J. Brown, IMID, OLED Workshop, Korea, 2007.

9 M. Ichikawa, N. Hiramatsu, N. Yokoyama, T. Miki, S. Narita, T. Koyama and Y. Taniguchi, Phys. Status Solidi RRL, 2006, 1(1), R37. 10 P. Kathirgamanathan, WO 00/32717, 08-06-200.

11 T. Sano, M. Fujita, T. Fujii, Y. Nishio and Y. Hamada, US Pat., 5456988, 10-10-1995.
12 (a) A. P. Kulkarni, C. J. Tonzole, A. Babel and S. A. Jeneke, Chem. Mater, 2004, 16, 4556; (b) G. Hughes and M. R. Bryce, J. Mater. Chem., 2005, 15, 94-107; (c) P. Kathirgamanathan, S. Surendrakumar, S. Ravichandran, R. R. Vanga, J. AntipanLara, S. Ganeshamurugan, M. Kumaraverl, G. Paramaswara and V. Arkley, Chem. Lett., 2010, 1222-1224.

13 D. Tanaka, T. Takeda, T. Chiba, S. Watanabe and J. Kido, Chem. Lett., 2007, 36, 262.

14 T. Miki, M. Nagaoka, S. Hayashi, Y. Taniguchi and M. Ichikawa, European Patent 1746094 A1, 24-01-2007.

15 S. Kusano, M. Koike, A. Takesue and M. Anzai, European Patent 1698613A1, 06-09-2006.

16 K. Okumoto, H. Kanno, Y. Hamaa, H. Takahashi and K. Shibata, Appl. Phys. Lett., 2006, 89, 63504.

17 M. Uchida, T. Koike, T. Izumizawa, K. Furikawa, US Pat., 6376694 B1, 23-04-2002.

18 P. Kathirgamanathan and S. Surendrakumar, WO 2009/112854 A1, 2009.

19 P. Kathirgamanathan and Y. F. Chan, WO 2008/081178, 2008.

20 D. Y. Kondakov, J. Appl. Phys., 2006, 99, 24901.

21 P. Kathirgamanathan, R. Price, S. Ganeshamurugan, G. Paramaswara, M. Kumaraverl, A. Parteepan, S. Selvaranjan, Juan Antipán-Lara and S. Surendrakumar, WO 2004/058913 A1, 2004.

22 M. J. Frazer and B. Rimmer, J. Chem. Soc. A, 1968, 2273.

23 D. F. Lewis and R. C. Fay, J. Chem. Soc., Chem. Commun., 1974, 1046.

24 Bruker, SMART version 5.624., Bruker AXS Inc., Madison, Wisconsin, USA, 2001.

25 Bruker, SAINT version 6.36A., Bruker AXS Inc., Madison, Wisconsin, USA, 2002.

26 G. M. Sheldrick, Acta Crystallogr., Sect. A: Found. Crystallogr., 2008, 64, 112.

27 F. H. Allen, O. Johnson, G. P. Shields, B. R. Smith and M. Towler, J. Appl. Crystallogr., 2004, 37, 335.

28 A. L. Spek, Acta Crystallogr., Sect. D: Biol. Crystallogr., 2009, 65, 148.

29 P. Kathirgamanathan, V. Arkley, S. Surendrakumar, Y. F. Chan, J. Antipán-Lara, S. Ganeshamurugan, M. Kumaraverl, G. Paramaswara and S. Ravichandran, SID Digest, 47.1, 701, 2008.

30 P. Kathirgamanathan, V. Arkley, S. Surendrakumar, Y. F. Chan, S. Ravichandran, S. Ganeshamurugan, M. Kumaraverl, J. AntipánLara, G. Paramaswara and V. R. Reddy, Soc. For Info. Display Digest, 2010, 32.2, 465.

31 M. Cole and W. Brutting, Physics of Organic Semiconductors, WileyVCH Verlag GmBH, 2005, pp. 95-128, ISBN-13: 978-3-527-40550-3.

32 P. Kathirgamanathan and M. K. Shepherd, J. Electroanal. Chem., 1993, 354, 305.

33 B. W. D'Andrade, S. Datta, S. R. Forrest, P. Djurovich, E. Polikarpov and M. Thompson, Org. Electron., 2005, 6, 11.

34 P. Kathirgamanathan and D. R. Rosseinsky, J. Chem. Soc., Chem. Commun., 1980, 839.

35 M. Era, Y. Ikeda, H. Tokuhisa and T. Tsutsui, Mol. Cryst. Liq. Cryst, 1999, 327, 171.

36 A. J. Heeger, I. D. Parker and Y. Yang, Synth. Met., 1994, 67, 23.

$37 \mathrm{~J}$. Antipán-Lara and P. Kathirgamanathan, IEEE Proc.: Optoelectron., 2000, 147, 369.

38 P. J. Haines, Thermal Methods of Analysis, Chapman \& Hall, London, 1995, ISBN 0751400505.

39 R. Greef, R. Peat, L. M. Peter, D. Pletcher and J. Robinson, Instrumental Methods in Electrochemistry, Ellis Horwood Ltd, 1985, ISBN: 0-85312-875-8 